\title{
Ecos de Sade em Piva
}

\author{
Clara Carnicero de Castro
}

Resumo: “Eu julgo tudo pelas sensações”, diz a protagonista da História de Juliette, grande romance clandestino de Sade. "Contra as responsabilidades pelas sensações", diz o eu lírico do poema "A catedral da desordem", de Roberto Piva. Conduzindo ao paroxismo a vulgata sensualista, o romancista forneceu os argumentos dos quais o poeta precisava para preconizar o desregramento integral das sensações e caucionar o exercício irresponsável e absoluto da liberdade. Neste artigo, analisaremos os empréstimos que o autor brasileiro fez do francês, repertoriando e sublinhando as semelhanças entre os dois escritores "malditos".

Palavras-chave: Roberto Piva, Sade, transgressão, sensações.

Abstract: "I judge everything by the sensations", says the protagonist of Juliette, Sade's major clandestine novel. "Against responsibility for sensations", says the speaker of Roberto Piva's "Cathedral's disorder" poem. By leading the sensualist vulgate to paroxysm, the novelist provided all the arguments of which the poet needed to preach sensations' complete disorder and guarantee the irresponsible and absolute exercise of freedom. In this article we intend to analyse the French author's influences on the Brazilian, compiling and stressing the similarities between the two "maudit" writers.

Keywords: Roberto Piva, Sade, transgression, sensations.

Este trabalho foi originalmente apresentado no Colóquio Internacional de Literatura Malditos nos Trópicos na Universidade Paris - Ouest - Nanterre - La Défense (França), em outubro de 2013. Para a escrita, tanto do texto em francês quanto do presente artigo em português, fomos beneficiados com bolsa de pós-doutoramento da Fundação de Amparo à Pesquisa do Estado de São Paulo (Fapesp). Agradecemos, portanto, à agência o financiamento concedido. 
Nos romances clandestinos de Sade, especialmente na História de Juliette (1801), a inserção do empirismo' de d'Holbach, Fréret e Condillac na narrativa de ficção culmina no seguinte preceito: "Deleitarmos não importa à custa de quem". ${ }^{2}$ Ainda que o marquês conduza ao extremo o sensualismo de seus contemporâneos, é preciso convir que o raciocínio dos libertinos é bastante lógico. Ora, se pensar é sentir, a gênese do saber se concretiza somente pela análise e comparação das diversas sensações. Daí a necessidade de variar e de aumentar gradativamente as impressões sensíveis. Diante dessa panóplia sensorial, as verdades morais ditas universais perdem qualquer legitimidade, pois a atividade mental passa a ser entendida como efeito de uma constituição física específica. Ou seja, o indivíduo é antes de tudo determinado pela sua organização corpórea, pelo ar que respira, pelos alimentos que ingere. Na História de Juliette, a abadessa Delbène traduz essa ideia pela metáfora do "som que resulta do choque da baqueta sobre a pele do tambor" (III, 190). Se não há causa física, como o choque da baqueta, não há fatalmente efeito intelectivo, no caso, o som do tambor. Como não somos mestres da nossa organização, não podemos nos opor aos efeitos dos choques que dela resultam. Somos dessa forma impelidos por uma necessidade irresistível à virtude ou ao vício. Seria, portanto, uma loucura e uma extravagância não fazer o que bem entendêssemos, e arrepender-nos das ações que nossa organização determinou, conclui a abadessa (III, 191).

Passados duzentos anos da morte do marquês, os preceitos de seus heróis ecoam do outro lado do Atlântico. Escrevendo em meio a uma sociedade talvez tão pudica e moralista quanto a setecentista, Roberto Piva se torna um escritor tão polêmico quanto o romancista francês. A faceta noturna de uma cidade caótica e imensa como São Paulo, onde o poeta passou a maior parte de sua vida, acolhe com efeito toda sorte de transgressões. Como um verdadeiro laboratório, a metrópole oferece "oportunidades infinitas" para o autor brasileiro "multiplicar e variar seu moto perpétuo do desregramento". Não obstante, a publicação da sua lírica se faz em surtos. São três grandes eclosões, cada

1. Sobre o empirismo chamado posteriormente de sensualismo, cf. Auroux, Sylvain. "Sensualisme". In: Delon, Michel (Org.). Dictionnaire européen des Lumières. Paris: PUF, 2010, pp. 1137-1140.

2. SADE, Donatien Alphonse François de. "Histoire de Juliette, ou les Prospérités du vice". In: CEuvres, edição de Michel Delon. Paris: Gallimard, Bibl. de la Pléiade, 1998, t. III, p. 225. As referências ao primeiro e terceiro tomos das Euvres de Sade (1990/1998) serão doravante indicadas no corpo do texto pelo número de tomo e de página.

3. Moraes, Eliane Robert. "A cintilação da noite”. In: PIVA, Roberto. Obras reunidas, vol. 2, edição de Alcir Pécora. São Paulo: Globo, 2006, p. 157. 
uma separada por longos doze anos de pausa editorial. A primeira irrupção ocorre no início dos anos 1960, depois entre os anos 1970 e 1980 e, por fim, dos anos 1990 até a primeira década do século XxI. ${ }^{4}$

Apesar da modernidade da poesia de Piva, o sensualismo radical de Sade nela sobressai. Basta procurar as inúmeras referências e reverências diretas que o poeta faz ao autor de Justine, a mais evidente sendo a "Homenagem ao Marquês de Sade",5 segundo poema do livro Piazzas. É verdade que muitas outras influências literárias e filosóficas marcam a obra do brasileiro, mas a apologia de um desejo todo-poderoso inscreve Piva no contexto literário e filosófico sadiano. Cabe frisar que não pretendemos examinar aqui os múltiplos aspectos da poética de Piva, cuja complexidade ultrapassa esta breve proposta de análise. Desejamos apenas explorar essa influência sadiana, mostrando como o escritor brasileiro emprega as ideias do francês. Para expor essas ressonâncias, seguiremos o princípio de "gradação", ${ }^{6}$ que rege os romances clandestinos do marquês, apresentando primeiro a transgressão como uma liberação dos sentidos e um ataque às convenções sociais, para em seguida sublinhar o deslizamento paulatino da experiência sensorial à experiência do mal.

\section{CONTRA AS PRIVAÇÕES, PELO DESREGRAMENTO ABSOLUTO}

A escrita de Piva se propõe como um "instrumento de Libertação Psicológica \& Total" $(\mathrm{O} 1,129)$. Ela investe contra a "burguesia" e seus quatro "fundamentos", a saber, "o cristianismo, o racionalismo cartesiano, a instituição da família e a ideologia do trabalho". A intenção do autor é justamente descreditar todos os interditos que a burguesia impõe, cujas "odiosas convenções sociais" $(\mathrm{O} 1,128)$ obrigam o sujeito a despojar-se de sua natu-

4. Cf. PÉcora, Alcir. "Nota do organizador". In: PIva, Roberto. Obras reunidas, vol. 1. São Paulo: Globo, 2005, pp. 9-10. Entre 2005 e 2008, os poemas de Piva foram reunidos pelo estudioso em três belos volumes: Um estrangeiro na legião (2005), Mala na mão \& asas pretas (2006) e Estranhos sinais de Saturno (2008). 5. Piva, Roberto. Obras reunidas, vol. 1. Op. cit., pp. 80-81. As referências aos três volumes das Obras reunidas de Piva (2005/2006/2008) serão doravante indicadas no corpo do texto pela abreviação "O", seguida do número do volume e da página.

6. Sobre a gradação, cf. Delon, Michel. Le Savoir-vivre libertin. Paris: Hachette, 200o, pp. 81-95.

7. Willer, Claudio. "Uma introdução à leitura de Roberto Piva”. In: Piva, Roberto. Obras reunidas, vol. 1. Op. cit., p. 145. 
reza, a desligar-se de sua sexualidade, condenando-o a um conflito eterno. O resultado de todas essas privações é um enorme mal-estar, ao mesmo tempo físico e mental. A libertinagem passa a ser então reivindicada como pulsão natural e a transgressão, como arma de combate contra as quimeras e as idealizações dos chamados bons costumes:

As cavilosas maquinações contra a Vida como consequência de um Eu Ideal (Deus, Pai, Ditador) nos obrigando a renúncias instintivas, nos transformando em conflituados neuróticos sem possibilidades de Brecha alguma, reduzindo a vício o nosso espontâneo interesse pelo sexo, o cristianismo como a escola do Suicídio do Corpo revelou-se a grande Doença a ser extirpada do coração do Homem (O1, 128-29).

Essa passagem do "Postfácio" de Piazzas lembra o começo da História de Juliette. Uma das primeiras lições ensinadas por Delbène à protagonista do romance é "anular perpetuamente os princípios [...] desse Deus fantasioso" (III, 195). Para a preceptora libertina, a educação moral contraria todos os movimentos da natureza ao desconsiderar “a extensão dos desejos físicos dos quais essa mãe [...] dotou os dois sexos" (III, 236). As privações que o decoro impõe são de fato tão cruéis e perigosas que prejudicam a prosperidade, a felicidade e a saúde de homens e mulheres (III, 237-38). A abadessa aconselha então a libertinagem, hábito que ela julga saudável, natural e conveniente a todos. Como se sabe, o próprio marquês abominava os interditos e a hipocrisia da religião. No relato Viagem à Itália, ele explicita sua indignação: "O que me revolta é o orgulho e a intolerância desses homens embatinados que, querendo se elevar muito acima de nós, mas compartilhando as mesmas fraquezas da natureza, são logo forçados a se colocar no mesmo nível pela impetuosidade das mesmas necessidades". E quanto às "renúncias instintivas", o marquês viveu tempo suficiente na prisão para atestar a nocividade de todas elas: "Vocês imaginaram fazer maravilhas [...] me reduzindo a uma abstinência atroz do pecado da carne. Pois bem, vocês se enganaram. Vocês inflamaram a minha mente e me fizeram formar fantasias que preciso realizar", protesta ele numa carta a sua esposa entre junho e julho de 1783 .

8. SADE, Donatien Alphonse François de. Voyage d'Italie ou Dissertations critiques, historiques et philosophiques sur les villes de Florence, Rome, Naples, Lorette et les routes adjacentes à ces quatre villes. Paris: Fayard, 1995, p. 318.

9. Id. 50 lettres du marquis de Sade à sa femme. Paris: Flammarion, 2009, p. 174 (itálico do autor). 
Como se Piva pudesse consolar as queixas do mestre francês, o eu lírico de "Porno-samba para o Marquês de Sade" convida o romancista ao pecado da carne na desordem noturna, quando a letargia diurna é substituída pela deliciosa agitação do luar: "A noite é nossa Cidadão/ Marquês, com esporas de gelatina pastéis de esperma \&/ vinhos raros onde saberemos localizar o tremor a sarabanda/ de cometas o suspiro da carne" $(\mathrm{O} 2,91)$. Se o dia prolonga a prisão e reduz o indivíduo à abstinência atroz e à inércia, a noite assegura o momento da atividade, da livre realização das fantasias: "no útero de maçã/ tudo começa/ a anoitecer/ cheio de energia” ( $\mathrm{O}_{2}$, 26). O crepúsculo, ao anunciar o período da liberdade, incita a "eclosão de uma força vital" ${ }^{10}$ outrora contida pelos grilhões diurnos. O direito à caminhada, que Sade prisioneiro exigia reiteradamente e seus algozes insistiam em recusar-lhe, é então restabelecido: "O Marquês de Sade/ \& a Marquesa de Santos/ caminham ao jazz do crepúsculo/ [...] gritando seus triunfos na escuridão" $\left(\mathrm{O}_{3}, 126\right)$. Em "Bules, bílis e bolas", o convite torna-se mais abrangente e a referência a Sade mais indireta. $\mathrm{O}$ eu lírico encoraja a extrapolação dos grilhões, chamados por ele de o torniquete da Consciência: "Nós convidamos todos a se entregarem à dissolução e ao desregramento./ A Vida não pode sucumbir ao torniquete da Consciência. A Vida/ explode sempre no mais além. [...]/ É preciso não ter medo de deixar irromper a nossa/ Alma Fecal” $(\mathrm{O} 1,137)$.

O chamado à irrupção da "Alma fecal" faz eco às manias escatológicas do ministro Saint-Fond. Na História de Juliette, o libertino sustenta "a supremacia do cu sobre a boceta e da matéria fecal sobre o esperma"." A vagina e o esperma, ligados à procriação e ao lícito, não portam nenhum valor transgressivo e reforçam as ilusões da sociedade. O ânus e as fezes conduzem, ao contrário, à prática subversiva e à aceitação da "verdade orgânica".12 Na poesia de Piva, o processo é similar: "contra a vagina pelo ânus, [...] contra Eliot pelo Marquês de Sade" $(\mathrm{O} 1,135)$, professa o eu lírico de "O Minotauro dos minutos". Em "A máquina de matar o tempo", a "ternura de lacinhos" e as "borboletas douradas" se dissipam na violência de uma "gastrite" e no "cintilante conteúdo das latrinas" $(\mathrm{O} 1,139)$. A alma fecal evoca dessa forma a energia homoerótica na imagem

10. Moraes, op. cit., p. 153 .

11. Cf. Delon, Michel. "Lobsession anale de Sade". In: Annales Historiques de la Révolution Française, Entre scatologie et fantasmes sexuels, le cul et son imaginaire, n. 3. Paris: Armand Colin/Société des Études Robespierristes, 2010, p. 142.

12. Ibid., p. 131. 
do gozo que jorra misturando-se a excrementos. Enérgico e subversivo, o gozo entérico explode o "torniquete da Consciência". A alma fecal libera enfim o sujeito do cerco de uma alma imaterial, cuja existência quimérica garante a indolência terrestre mediante a promessa de uma vivacidade celeste.

No "Manifesto utópico-ecológico em defesa da poesia \& do delírio", o "torniquete da Consciência" se estende para o "torniquete da civilização" $\left(\mathrm{O}_{2}, 143\right)$. Ou seja, o superego do sujeito se expande no "Superego da Sociedade" $(\mathrm{O} 1,131)$, tornando o sofrimento individual um verdadeiro suplício coletivo. Deus, Pai e Ditador são os três representantes da autoridade social, cujo poder se mantém unicamente por crenças pueris. As ilusões da religião, da família e do governo dopam o físico e desorientam o mental. Daí o "Suicídio do Corpo" e o nascimento do "conflituado neurótico", do qual falava o "Postfácio". Aqui, trata-se de mostrar como a civilização destrói o indivíduo paulatina e dissimuladamente até destituí-lo de seu "núcleo biológico" e de seu "espaço vital".

De novo, a renúncia aos imperativos dos sentidos causa um mal-estar físico e mental, impedindo o sujeito de pensar por si mesmo, alienando-o do mundo: "Estamos sendo destruídos em nosso núcleo biológico,/ nosso espaço vital \& dos animais está reduzido a/ proporções ínfimas/ quero dizer que o torniquete da civilização está/ provocando dor no corpo \& baba histérica/ o delírio foi afastado da Teoria do Conhecimento" $\left(\mathrm{O}_{2}, 143\right)$. No intuito de rechaçar a instituição perniciosa da família cristã, o marquês já havia sido invocado no "Postfácio". Somente a "liberdade sexual absoluta" pode extirpar do coração do indivíduo a "grande doença" ou a idealização quimérica das normas sociais: "em contraposição às passeatas da Família com Deus pela Castidade, \& a toda manifestação deste fã-clube-de-Deus, nós oporemos a Liberdade Sexual Absoluta em suas mais extremadas variações levando em conta a solução do Marquês de Sade para quem a Justiça é a Santidade de Todas as Paixões" (O1, 131). Como se vê, é o próprio setecentista que, tal qual um anjo, "protege" o eu lírico contra esse "surdo século de quedas abstratas" $(\mathrm{O} 1,81)$.

A crítica da autoridade em Sade pode ser evidenciada pelo ministro Saint-Fond, o representante de todos os vícios dos governos despóticos. Segundo o herói, para sujeitar os homens e fazê-los obedecer voluntariamente, é indispensável aliar o trono ao altar, pois "as correntes sacerdotais [...] reforçam as da política" (III, 458). Quanto à autoridade patriarcal, o amigo íntimo do celerado, Noirceuil, professa a Juliette um elogio do parricídio para convencê-la a matar o pai do ministro. Seus argumentos visam a desconstruir todas as bases da instituição familiar: o reconhecimento filial supõe, na verdade, um preconceito, porque a natureza não indica à prole seu progenitor; o amor 
ao próprio pai mostra-se portanto um erro, sendo por consequência "natural" atentar contra sua vida (III, 400-02). Noutra passagem, Noirceuil revela que, pelo pouco que as leis asseguram ao indivíduo, "elas o despojam absurdamente" (III, 334), propondo a volta ao "estado de incivilização no qual a natureza nos criou". Ainda que neste o mais fraco tenha que "se garantir de uma força e de uma guerra aberta", no estado civil, o libertino acredita ser "impossível fazer valer, para se defender, o pouco que [o mais fraco] recebeu da natureza" (III, 335). Em nota, Sade esclarece o raciocínio de seu herói: ainda que o homem faça novas leis todos os dias para tornar-se mais feliz, cada lei que ele inventa tira "uma porção de sua felicidade: e por que tantas leis? Ora, é preciso que os tratantes enriqueçam e que os tolos sejam subjugados. Eis, numa palavra, todo o segredo da civilização dos homens" (III, 335).

O eu lírico do "Manifesto da selva mais próxima” propõe igualmente um modo de vida alternativo, caótico e anárquico, similar ao estado de incivilização de Noirceuil: "É do Caos, da Anarquia social que nasce a luz enlouquecedora da Poesia/ Criar novas religiões, novas formas físicas, novos antissistemas políticos, novas formas de vida/ Ir à deriva no rio da Existência" $\left(\mathrm{O}_{2}, 149\right)$. Essa vida anárquica implica, porém, a renúncia à paz e à inércia. A "luz enlouquecedora da Poesia" nasce com efeito da destruição de todos os fundamentos da burguesia, que são frágeis, pois ilusórios. No "Poema porrada", a violência se apresenta como motor da mudança social, o veículo que leva o indivíduo à deriva da existência: "Eu estou farto de muita coisa/ não me transformarei em subúrbio/ não serei uma válvula sonora/ não serei paz/ eu quero a destruição de tudo que é frágil:/ cristãos fábricas palácios/ juízes patrões e operários" $(\mathrm{O} 1,66)$.

Tal relação entre energia e violência, apatia e paz seria talvez uma lição que Piva aprendeu com seu mestre francês. O panfleto "Franceses, mais um esforço se vocês quiserem ser republicanos" ensina que, para "manter a perpétua agitação imoral da máquina", não devemos ser "muito morais, porque o estado moral de um homem é um estado de paz e de tranquilidade, e seu estado imoral é, ao contrário, um estado de movimento perpétuo" (III, 129, itálico do autor). Nos dois autores, a ideia de virtude conduz à inércia (à "domesticação da vontade"), ${ }^{13}$ enquanto a ideia de vício, no sentido de transgressão dos bons costumes, coloca em valor a agitação (o choque enérgico). A paz e a tranquilidade (atribuídas à virtude passiva) se opõem à energia do indivíduo imoral, cujo poder desestabiliza tudo. Nesse sentido, tanto o poeta quanto

13. PÉCORA, op. cit., vol. 2, p. 12. 
o romancista rejeitam o interesse coletivo a favor do interesse particular e manifestam a revolta contra o pacto social. Eles compartilham ainda a oposição a todos aqueles que querem assegurar a tranquilidade pública anulando as paixões. A arte da escrita se estabelece então como um meio de liberação do indivíduo dos grilhões impostos pelo moralismo social:

O objetivo de toda Poesia \& de toda Obra de Arte foi sempre uma mensagem de Libertação Total dos Seres Humanos escravizados pelo masoquismo moral dos Preconceitos, dos Tabus, das Leis a serviço de uma classe dominante cuja obediência leva-nos preguiçosamente a conceber a Sociedade como uma Máquina que decide quem é normal \& quem é anormal. Para a Sociedade Utilitarista do nosso tempo, a prova máxima de normalidade é a adaptação do indivíduo à família \& à comunidade. Numa sociedade assim estruturada, todas as virtudes, digo Todas, estão a serviço do Princípio de Utilidade (O1, 130).

Ora, se todas as virtudes são definidas segundo o princípio da utilidade pública, o vício representa, por oposição, o princípio do prazer. Assim, considerado anormal para a sociedade, já que não se adapta às conveniências, o prazer conduz inevitavelmente ao crime. Daí que o vício passa a ser concebido como sinônimo de energia e de autonomia do indivíduo. O distanciamento das regras sociais e civis implica a extinção do remorso - sentimento inútil e próprio dos fracos, produzido por uma consciência ainda torturada pelo torniquete. $\mathrm{O}$ arrependimento nada mais é que medo de agir contra as proibições. Basta, portanto, anular tal sentimento para usufruir de um novo universo: "levei a imprudência e o crime, a libertinagem e a infâmia ao último grau; e se experimento algum remorso, declaro bem sinceramente que ele só se deve ao desespero de não ter feito mal o bastante" (III, 342). Trata-se do autorretrato de Noirceuil, que ecoa no autorretrato do eu lírico de "Ode a Fernando Pessoa":

Resumirei para Ti a minha história:/ Venho aos trambolhões pelos séculos,/ Encarno os fora-da-lei e todos os desajustados,/ Não existe um gangster juvenil preso por roubo e nenhum louco sexual que eu/ não acompanhe para ser julgado e condenado;/ Desconheço exame de consciência, nunca tive remorsos, sou como um lobo dissonante nas lonjuras de Deus $(\mathrm{O} 1,24)$. 


\section{DO SENSUALISMO À EXPERIÊNCIA DO MAL}

Para alcançar o gênero de transgressão ao qual Sade e Piva visam, é preciso contudo refinar o vício antes de amplificá-lo. Numa carta a sua mulher e em muitos de seus romances, $o$ marquês desenvolve o "princípio de delicadeza": ${ }^{14}$ um "refinamento sensual"15 que conduz "cada um à sua própria libertinagem". ${ }^{16}$ Trata-se, mais precisamente, de um desvio singular, irredutível às normas e capaz de impor ao deboche uma marca individual, um "sabor próprio". ${ }^{17} \mathrm{Ou}$ seja, toda ideia de prazer universal está excluída do conceito de "delicadeza", no qual a bizarrice impera sozinha. Se em Piva não encontramos o termo, a ideia lhe é bastante familiar. Primeiro pelo excesso das sensações descritas, depois pelas imagens de diversas percepções sensoriais misturadas e, por fim, pela singularidade destas. Na "Ode a Fernando Pessoa”, os transportes da mesa são exacerbados pela contravenção do calote e pelo retorno da refeição ingerida suscitando uma "circulação perversa do alimento":18 "Agora, vem comigo ao Bar, e beberemos de tudo nunca passando pelo caixa,/ Vamos ao Brás beber vinho e comer pizza no Lucas, para depois vomitarmos/ tudo de cima da ponte" $(\mathrm{O} 1,23)$. Em "O próprio Bodidarma respondeu", a "delicadeza" atinge um grau ainda mais elevado, quando comida e bebida são misturadas a fluidos corporais: "Só acredito na geleia genital/ ânus solar/ azeitona com pimenta \& vinho rosé" $(\mathrm{O} 2,128)$. E para terminar esse "dandismo erótico", ${ }^{19}$ chega-se às extravagâncias mais singulares. Em "Osso \& Liberdade", o poeta traça o retrato de um libertino cujo princípio de delicadeza consiste em ser sodomizado por damas munidas de consolos, comer carne de tatu assada e colecionar amantes a fim de envenená-los:

Onça Humana quis saber se Pólen conhecia um garoto meio/ pirado chamado Oscar Amsterdam que tinha vícios/ requintados \& que gostava de ser comido por mulheres/ aparelhadas com falos de borracha \& que gostava de se/ banquetear com carne de tatu assado no restaurante/ Sujinho aos sábados \& colecionar amantes revisionistas para envenená-los [...] (O2, 60-61).

14. Cf. Delon, Michel. Le Principe de délicatesse: Libertinage et mélancolie au XVIII siècle. Paris: Albin Michel, 2011, pp. 15-16 e pp. 295-297.

15. Id., p. 15 .

16. Id., p. 296.

17. Ibid.

18. Id. Le savoir-vivre libertin, op. cit., p. 178.

19. Le Brun, Annie. Soudain un bloc d'abîme, Sade. Paris: Gallimard, 1986, p. 146. 
O personagem sadiano que oferece um excelente exemplo de deboche pesquisado é Braschi, o papa Pio vi da História de Juliette. O desvio do herói se mostra ainda mais chocante já que ele é o próprio chefe da Igreja. Juliette narra a delicadeza coprofágica do pontífice durante seu primeiro banquete no Vaticano: "Era preciso com frequência que eu triturasse os alimentos que ele queria comer, eu os umedecia com minha saliva e os passava à sua boca. A minha se enxaguava com os vinhos que ele desejava beber, ele os injetava às vezes no meu cu e os engolia. Se por azar neles se misturavam alguns cocôs, ele ficava nas nuvens" (III, 868). Trata-se da mesma circulação perversa do alimento nuançada na lírica de Piva. Em Sade, porém, a coprofagia configura apenas o início da transgressão. A sensibilidade física, entendida como o efeito de um fluido elétrico que circula pelo corpo no interior dos nervos, implica um choque entre partículas elétricas. O choque mais violento possível dessas partículas produz o maior prazer possível e permite ao libertino sentir sua existência intensamente. ${ }^{20} \mathrm{O}$ vício está, por conseguinte, ligado intrinsecamente a este "intensivismo", ou seja, ao "ideal do maior choque dado ao recebido". ${ }^{21}$ Em outras palavras, todas as vezes em que o libertino incita o choque mais violento possível numa vítima, ele provoca em seu próprio fluido elétrico, como num contragolpe, outro gênero de choque, cuja intensidade é equivalente, mas os inconvenientes nulos. ${ }^{22}$

Embora Piva não faça uso da noção de fluido elétrico, a relação entre prazer e eletricidade também lhe é familiar. O "Sindicato da Natureza" sustenta, por exemplo, que "Todos nós somos labaredas provocadas pelo curto-circuito do Desejo" $\left(\mathrm{O}_{3}, 187\right)$. E em "O Minotauro dos minutos", o "êxtase açucarado" é colocado em contraposição ao "curto-circuito", à "escuridão" e ao "choque" $(\mathrm{O} 1,135)$. Toda a subversão que a poesia de Piva objetiva está, na verdade, impregnada desse "intensivismo" sadiano. No caso do poeta, o objetivo é "amplificar a intensidade do ato erótico para predispor o sujeito lírico ao delírio". ${ }_{23}$ Para aumentar a transgressão, o choque deve ser cada vez mais intenso e pouco importa como ou à custa de quem. A radicalização do excesso na lírica do brasileiro passa, portanto, fatalmente pela violência. A respeito dos libertinos

20. Cf. Deprun, Jean. "Sade et le rationalisme des lumières". In: Leduc, Victor (Org.). Raison Présente, n. 3. Paris: Éditions Rationalistes, 1967, p. 81.

21. Ibid.

22. Id., pp. 82-83.

23. Moraes, op. cit., p. 158. 
sadianos, Michel Delon explica: “A partir do momento em que todo 'prazer honesto' é recusado por princípio, é a transgressão que se torna motor do desejo e a narrativa é tomada por uma dinâmica vertiginosa que conduz sempre mais longe na agressão, na negação e na destruição das vítimas". ${ }^{24}$ À imagem destas, a presa do eu lírico de "Afetando profundamente o emocional (Antínoo, ragazzo di marbro)" deve se humilhar e experimentar as impressões mais vivas possíveis: "suas coxas se retesam/ \& você chora um pouco/ venha, lamba minha mão \&/ se prepare para um milhão/ de comas loucas loucas" $\left(\mathrm{O}_{2}, 38\right)$. Como o herói libertino, o eu lírico encontra seu prazer "através dos objetos externos e do eco interno que eles suscitam". ${ }^{25}$ Por fim, basta comparar as paixões duplas, criminosas e assassinas de "Os Cento e Vinte Dias de Sodoma" com os "Apavoramentos de Coxas sex fiction \& delírios" para proclamar Piva como o digno herdeiro do marquês nos Trópicos:

Segunda parte, paixões duplas: 134 . Ele só flagela meninos de catorze a dezesseis anos e os faz gozar em sua boca depois. Ele dá cem golpes em cada; ele recebe sempre dois ao mesmo tempo (I, 324).

Terceira parte, paixões criminosas: 83. Ele lhe queima, com um fósforo, os pelos das pálpebras, o que a impede de ter qualquer descanso à noite, nem de poder fechar os olhos para dormir (I, 338).

Quarta parte, paixões assassinas: 98. Um homem que gostava de queimar levemente retifica o suplício, assando suas vítimas sobre uma grelha $[\ldots](\mathrm{I}, 364)$.

Apavoramento n. 1: dezoito garotos \& dezoito garotas foram emparedados vivos/ em caixas construídas com chicletes que só Adams fabrica \&/ tostados dentro de um porão de arsênico \& cascavéis $\left(\mathrm{O}_{2}, 54\right)$.

Apavoramento n. 2: quinze adolescentes de ambos os sexos foram chicoteados na/ bunda por batalhões da TFP que os insultavam enquanto/ trezentos rapazes \& moças de seita imperialista Igreja Católica/ cortavam rodelas de cebola \& colavam em seus olhos $\left(\mathrm{O}_{2}, 55\right)$.

24. Delon. Le Principe de délicatesse, op. cit., p. 297.

25. Id. L'Idée d'énergie au tournant des Lumières (1770-1820). Paris: PUF, 1988, p. 281. 
Postas todas essas semelhanças, cabe reconhecer que a poética de Piva é muito mais nuançada que a ficção romanesca do marquês. As ideias radicais dos libertinos são, pois, apenas insinuadas pelo eu lírico. Seguramente porque a poesia é um gênero mais sugestivo que o romance filosófico, cujos recursos permitem ao autor estender uma discussão, aprofundar um assunto ou precisar os detalhes escabrosos de uma orgia. A isso se acrescenta o fato de que os argumentos dos heróis sadianos se baseiam numa "ciência imperfeita", "intuitiva", ${ }^{26}$ quase inteiramente retificada na época de Piva. Além disso, sabemos que o brasileiro fez empréstimos de inúmeras outras fontes, cujas influências podem facilmente suplantar a do marquês. É por isso que seria absolutamente equivocado reduzir a obra do escritor dos Trópicos à do romancista do velho mundo. Ainda assim, nosso trajeto demonstra que o legado de Sade na lírica de Piva é inequívoco. Afinal, tudo na obra do poeta é julgado pelas sensações. Nesse aspecto, pode-se dizer que a poesia do brasileiro se estabelece como um eco bicentenário do sensualismo sadiano.

Seja enfim lírica do desregramento ou prosa da transgressão, da virada do século Xx ou do século XviII, o importante é que tanto Piva quanto Sade fazem da arte da escrita "a mais fascinante Orgia ao alcance do Homem" $\left(\mathrm{O}_{1}, 129\right)$ e mergulham o leitor num "delírio do qual [...] é impossível se dar conta" (III, 311). Diante desse magnífico banquete, só nos resta escolher nosso prato e, a exemplo do poeta, abrir os olhos e dizer “Ah!” $(\mathrm{O} 2,22)$.

Clara Carnicero de Castro é doutora em Filosofia pela usp. Realizou estágio doutoral e pós-doutoral na Universidade Paris-Sorbonne iv e, atualmente, dá continuidade ao pós-doutorado na usP. É autora dos artigos "Le Fluide électrique chez Sade" (Dix-Huitième Siècle, n. 46, 2014) e "Entre le Crime et la sensibilité: Les paradoxes du personnage de Clairwil" (Itinéraires. Littérature, textes, cultures, n. 2, 2013), além do livro Os libertinos de Sade (Fapesp/lluminuras, no prelo).

26. Deprun, Jean. "Sade et la philosophie biologique de son temps". In: De Descartes au romantisme: études historiques et thématiques. Paris: J. Vrin, 1987, p. 147. 